\title{
Economic Hardship and Well-Being: Examining the Relative Role of Individual Resources and Welfare State Effort in Resilience Against Economic Hardship
}

\author{
$\operatorname{Tim}_{\text {Reeskens }}{ }^{\text {(D) }} \cdot$ Leen Vandecasteele $^{2}$
}

Published online: 18 January 2016

(C) The Author(s) 2016. This article is published with open access at Springerlink.com

\begin{abstract}
With the aftermath of the economic crisis starting to fold out, the extent and the conditions under which the experience of economic hardship thwarts subjective well-being spark academic interest. In this paper, we examine the cushioning impact of three immaterial buffers embedded within civil society-namely social networks, religiosity, and confidence in politics - in combination with the cushioning role of the welfare state. Analyzing the 2010 wave of the European Social Survey, the results confirm that the experience of economic hardship is inversely related to happiness. All three proposed protective measures cushion the negative impact of economic strain on happiness, whereby the positive effect of social networks and confidence in politics is stronger in countries with lower levels of social expenditure. The latter finding provides some evidence for the crowding out-thesis but mainly suggests that a strong welfare state can take over the role of protective buffers in civil society, which is helpful as such buffers are less present among the most vulnerable social groups. The results of the analysis are discussed in relation to social science research and public policy.
\end{abstract}

Keywords Subjective well-being - Economic hardship $\cdot$ Resilience $\cdot$ Crowding-out thesis - Comparative welfare state analysis · European Social Survey

Tim Reeskens

t.reeskens@tilburguniversity.edu

Leen Vandecasteele

leen.vandecasteele@uni-tuebingen.de

1 Department of Sociology, Tilburg University, PO Box 90153, 5000 LE Tilburg, The Netherlands

2 Department of Sociology, University of Tuebingen, Wilhelmstrasse 36, 72074 Tuebingen,

Germany 


\section{Introduction}

The economic crisis has caused growing interest among social scientists to study not only the extent but also the conditions under which the experience of economic hardship affects subjective well-being. Evidence suggests that the experience of poverty and deprivation have a significant bearing on subjective well-being (Hagerty 2000; Diener et al. 1999; Gudmundsdottir 2013). At the same time, studies hint at a variation in the extent to which economic hardship affects well-being; some people are more resilient in the face of economic hardship than others. To explain this variation, studies have largely focused on the cushioning impact of material or pecuniary resources, and particularly welfare states' ability to buffer the negative consequences of economic hardship (Stuckler et al. 2009; Visser et al. 2014).

Less examined is the moderating role of immaterial or non-monetary resources that accrue from civil society. ${ }^{1}$ Although civil society actors appear in many forms, here we focus on whether social networks, religious participation and confidence in politics protect actors against the expected negative relationship between economic hardship and subjective well-being. ${ }^{2}$ Firstly, we propose that social networks moderate the effect of economic hardship on well-being because social ties are made up of material but foremost immaterial resources that can be mobilized in times of need (Reeskens and van Oorschot 2014). Second, religion has shown to provide an encompassing framework and existential security for those facing economic hardship (Immerzeel and van Tubergen 2013). Third, we argue that confidence in politics also cushions the effect of economic hardship on wellbeing (van den Bos et al. 1997; Thibaut and Walker 1975), as it fosters the belief that the government can tackle poverty. ${ }^{3}$

When studying how these selected immaterial protective buffers lead people to be resilient in the face of economic hardship, the competing role of material buffers as provided by the welfare state cannot be left untouched. While welfare state effort alleviates the negative consequences of economic shocks (Stuckler et al. 2009), it can be argued that resources accruing from civil society are equally efficient in cushioning the negative impact of experienced hardship (Popenoe 1988). The 'crowding out' hypothesis emphasizes that in providing support, the welfare state undermines the quality of traditional support mechanisms, such as social networks, religious institutions, and civil society at large (Fukuyama 2001). Therefore, to fully understand the role of protective immaterial buffers in achieving well-being for those experiencing hardship, it is important to understand if their effect is weaker in larger welfare states.

To study the complex relationship between experienced economic hardship and subjective well-being, as well as the moderating role of immaterial resources of social

\footnotetext{
1 As often argued by students of political sociology, defining 'civil society' can be similar to opening Pandora's box. In this contribution, we follow Michael Walzer (1995, p. 7) who defines civil society as the "space of uncoerced human association and also the set of relational networks-formed for the sake of family, faith, interest, and ideology—that fill this space."

2 As outlined above, 'civil society' is a broad concept. Alongside informal social networks, religious involvement and confidence in politics, an additional component comprises of involvement in voluntary associations (Putnam 2000). Due to data limitations, we have opted to focus on the first three components.

3 We are aware of the fact that endogeneity and reversed causality may influence our results. In spite of evidence that supports our causal order (Dolan et al. 2008), it could be plausibly assumed that happiness levels affect people's level of social interaction, religious participation and trust in politics. In any case, throughout our study we are aware of the limitations of our design and it should be noted that our focus is on associations and moderating relationships rather than on causal effects.
} 
networks, religiosity, and confidence in politics, across different welfare states, we analyze the 2010 European Social Survey. In this survey, representative samples of 24 countries have been questioned about, among other issues, their experienced deprivation in the last 3 years (Visser et al. 2014; Reeskens and van Oorschot 2014). Before we turn to the empirics, we first of all build up our theoretical argument in section two. In the third section, we discuss the consulted data and the analytical strategy in greater detail. The results of the analysis are presented in the fourth part of the article. The fifth and final section discusses the implications of our findings for social science and social policy.

\section{Literature Review}

\subsection{Deprivation and Well-Being}

The question of whether money can buy happiness-the famous Easterlin paradox (1974) - is an enduring puzzle of social science scrutiny (Ferrer-i-Carbonell 2005). The relationship between economic resources and well-being is well established but not linear. While the effect of income gains on well-being is on average rather small, it is found to be stronger for lower income groups and becomes weaker in higher income groups (for a review, see Diener and Oishi 2000; Clark et al. 2008; Diener and Biswas-Diener 2002). Additionally, research shows that income losses have a stronger effect on life satisfaction than income gains (Wolbring et al. 2013). Hence, especially people with economic difficulty suffer from lower levels of well-being.

Two theoretical frames aim to explain why economic hardship thwarts well-being (Diener and Biswas-Diener 2002; Wolbring et al. 2013). Firstly, income is essential for covering basic needs; shelter, clothing and food. A higher income provides individuals with more financial assets to satisfy their needs, which in turn should increase their happiness (Ferrer-i-Carbonell 2005).

A second approach indicates that in order to explain individual well-being, the absolute income level is of subordinate importance to relative positions (Easterlin 1995; Ferrer-iCarbonell 2005; Clark et al. 2008). From social comparison theory (Festinger 1954), it is known that individuals tend to compare their situation with that of others, or to their previous situation. As Easterlin (1995, p. 36) argues: "happiness, or subjective well-being, varies directly with one's own income and inversely with the income of others." Especially when individuals perceive their position as unfavourable and feel relatively deprived, negative consequences are experienced.

This approach to social comparison is suitable to explain the consequences of experienced economic shock on well-being. First of all, due to over-time comparisons, people who see that they now are less prosperous than before are expected to report lower levels of well-being. Second, if the economic setback does not happen to others in society, social comparison theory predicts that this person will be less happy because his or her relative economic situation is decreased compared to other people.

A subsequent, frequent question is whether an upward or downward change in material prosperity has long-lasting effects on people's well-being (Wolbring et al. 2013; Brickman and Campbell 1971). Several studies have shown that some level of adaptation to income increases occurs such that when people's income keeps rising, happiness levels remain the same. Furthermore, people tend to gravitate back to their previous happiness level once the initial phase of increased happiness subsides (DiTella et al. 2007). Interestingly, this 
adaptation effect has not been found for income loss (Burchardt 2005; Clark et al. 2014). The detrimental effects of economic losses on well-being are longer lasting. The combination of studies of deprivation on indicators of well-being leads to the formulation of our first hypothesis (H1) is: The experience of economic hardship is negatively related to wellbeing.

The research to date examining the effects of changes in material prosperity on happiness has mainly focused on income in general, and on income increases in particular. Given the stronger well-being effects of income declines (Wolbring et al. 2013) and its longer-lasting negative effects (Burchardt 2005; Clark et al. 2014), it is opportune for research to focus on the conditions under which a decline in living standards has negative well-being effects. Furthermore, changes in income overlook other elements of the standard of living that may have a more direct relationship with happiness. For instance, when income falls, people may have savings or material goods to fall back on, or they may even have voluntarily reduced their employment (Diener and Biswas-Diener 2002). Gudmundsdottir (2013) found that in the 2008 economic recession in Iceland, income and unemployment did not predict happiness, but a respondent's assessment of financial difficulties did. Therefore, this study focuses on economic hardship, measuring a broader concept of deprivation.

\subsection{Buffering the Consequences of Economic Hardship}

Some studies of the effect of economic hardship on well-being show heterogeneity in this relationship, suggesting that among those experiencing deprivation, some may rely on resources that provide resilience against the negative well-being effects of economic hardship (Myers and Diener 1995; Diener and Biswas-Diener 2002). In our contribution, we highlight protective resources that are largely of immaterial nature and embedded in civil society, namely informal social contacts, religiosity, and confidence in politics.

The positive effect of social contact on well-being is well-documented (Kawachi et al. 1999; Helliwell and Putnam 2004). Social interactions reduce stress, they encompass material and immaterial resources, improve access to health care, and enable social control to discourage behavior that may prove harmful for one's well-being. Famously, Putnam (2001, p. 44) argued that "your chances of dying over the course of the next year are cut in half by joining one group, and cut to a quarter by joining two groups."

While the positive relationship between social contact and well-being has been demonstrated, studies also show that when experiencing economic hardship the mobilization of social capital can make people more resilient. Scholars often argue that bonding networks allow the deprived to "get by" by instantly mobilizing resources to relieve their deprivation; thin or bridging networks, alternatively, are needed to "get ahead" by, for instance, providing job offers that flow between weak ties (Putnam 2000; de Souza Briggs 1998; Narayan 1999). On the other hand, immaterial support from networks might buffer the stress and lower self-esteem associated with economic hardship (De Silva et al. 2005; Uphoff et al. 2013). Therefore, the second hypothesis states: social ties positively moderate the negative relationship between socioeconomic hardship and well-being (H2). Put differently we expect that those encountering economic distress and are well integrated in social networks will be happier than those encountering economic hardship without these networks.

Secondly, studies propose that religiosity can cushion the negative impact of experienced deprivation on well-being. The direct effect has been studied repeatedly (Ellison and Levin 1998; Lim and Putnam 2010), with a causal mechanism that encompasses two 
processes (for a review, see George et al. 2002). A first traditional argument is that social integration explains the link between religiosity and well-being (Durkheim 1951 [1897]). Pious Europeans might benefit from interactions with like-minded churchgoers through the support, companionship and a sense of belonging that reside in general social ties; studies in particular show the "supercharging" effect of a religious common interest with friends (Lim and Putnam 2010), which increases well-being more than general friends. This private tie to God could also help improve well-being, since religious devoutness offers "a comprehensive framework for the interpretation of world events" which positively affects well-being (Lim and Putnam 2010; Emmons et al. 1998; Immerzeel and van Tubergen 2013). Religious people have a stronger external locus of control, making them more likely to believe that their deprivation will be alleviated by an external source. The third hypothesis $(\mathrm{H} 3)$ thus reads: religiosity positively moderates the negative relationship between economic hardship and well-being. In other words, religious people who experience economic hardship are expected to be happier than non-religious, deprived Europeans.

The third mechanism is concerned with the beneficial effects of confidence in political institutions. A number of empirical studies regarding the Fairness Heuristics Theory hint at the importance of the perceived fairness of institutions on satisfaction with various outcomes (Thibaut and Walker 1975; van den Bos et al. 1998). People who believe in the fairness of institutions generally have higher political trust (Bovens and Wille 2008) and hence we would expect them to be happier than people with less political trust. Furthermore, evidence exists that people who value compliance with government are generally happier. Helliwell (2003) showed that people who are strongly against cheating on taxes express higher levels of well-being. Given the strong link between the preference for law compliance and political trust (Marien and Hooghe 2011), we assume that those confident in politics will also score higher on indicators for well-being. Although there is evidence that people who have seen their economic situation decrease are more skeptical towards politics (see Catterberg and Moreno 2006), our specific interest is in the moderating effect of confidence in politics on the link between experienced deprivation and well-being. People experiencing economic hardship who still put their confidence in politics might think that politicians will be able to end the struggle. Similar to the external locus of control argument proposed for the positive effect of religiosity, the sense of control given to politicians might result in higher subjective well-being. This leads to the fourth hypothesis (H4): Confidence in politics positively moderates the negative effect of economic hardship on well-being. Impoverished Europeans who have confidence in politics will be happier than those who are deprived and do not trust politics.

\subsection{The Impact of the Welfare State}

When discussing how protective buffers from civil society moderate the impact of experienced economic hardship on well-being, it should be acknowledged that the mobilization of these buffers might compete with support from the welfare state. This reflection on the competing role of welfare state provision suggests that in order to provide happiness among the most deprived, mobilizing social networks, relying on religion and having trust in government is mostly relevant in weaker welfare states and less important in wellestablished welfare states. This idea has been articulated by happiness expert Ruut Veenhoven (2000), who finds no confirmation for higher levels of well-being in countries with high per capita spending on social protection. Further evidence shows that the wellbeing of the unemployed does not depend on the generosity of the welfare state (Ouweneel 
2002). Reflecting on this remarkable null-finding, Veenhoven (2000, p. 113) considers the idea that by delivering material and immaterial support-necessary for happiness-the welfare state is in competition with other service providers, in particular family and friends, but also the church (Popenoe 1988).

The suggestion that generous welfare provision erodes the supportive role of immaterial resources, especially from social networks and church, is quite dominant among US neoliberal scholars (Etzioni 1995; Fukuyama 2001). Fukuyama (2001, p. 18) argued that welfare state intervention are among those "activities that are better left to the private sector or to civil society." Empirical evidence on this 'crowding out' thesis, and whether the quality of civil society support is weaker in more generous welfare states, is scattered and inconclusive. Proponents of the 'crowding out' proposition often focus on the exceptional American case in which the quality of networks of family, friends and church, has steadily declined (Popenoe 1988; Fukuyama 2001), whereas opponents of this thesis often study varying levels of social capital across welfare states, discarding the study of the quality of networks (van Oorschot and Arts 2005).

Empirical evidence that addresses the question of whether more generous welfare states erode the role of immaterial protective buffers in supporting well-being among the deprived is scarce, urging us to borrow related findings. In a recent study evaluating the 'crowding out'-thesis, Reeskens and van Oorschot (2014) discovered that whereas experienced deprivation was lower in more generous welfare states, precisely in these more generous welfare states social networks did less to prevent deprivation. Put differently, individuals in weaker welfare states rely more on their networks to prevent poverty. We expect to find the same cross-national patterns for the role of social networks, religiosity and political trust. In summary, we propose that welfare state effort negatively moderates the effect of immaterial resources on well-being among the deprived (hypothesis H5). In other words, in encompassing welfare states social networks, religion and confidence in politics are less relevant for improving the well-being for people in economic hardship.

\section{Data and Methods}

The analysis is based on 24 OECD countries of the 2010 European Social Survey (ESS Round 5, 2011), a comparative biennial survey project that was carried out in more than 25 countries. We excluded students ${ }^{4}$ and ended up with 39,859 respondents, ranging from 944 respondents in Cyprus to 2462 in Greece. ${ }^{5}$

\subsection{Dependent Variables}

The interest of this article is on individual well-being, which is proxied by the happinessitem "Taking all things together, how happy would you say you are?" with a 0-10 scale ranging from 'extremely unhappy' (0) to 'extremely happy' (10). This item, or its variant

\footnotetext{
${ }^{4}$ Studies have found that income correlates less strongly with subjective well-being for students (Veenhoven and Ehrhardt 1995). This is attributed to the lifestyle of students, the material support they receive from their families and the temporary nature of their lower economic resources.

5 The countries studied are: Belgium, Bulgaria, Croatia, Cyprus, Czech Republic, Denmark, Estonia, Finland, France, Germany, Greece, Hungary, Ireland, Latvia, The Netherlands, Norway, Poland, Portugal, Slovakia, Slovenia, Spain, Sweden, Switzerland, and The United Kingdom.
} 
offered in the World Values Study, has also been studied in relation with material wealth (Layard et al. 2008).

\subsection{Independent Variable}

The independent variable 'economic hardship' measures self-reported deprivation in the last 3 years. This variable is a latent scale composed out of three items tapping into the extent to which the respondent, in the last 3 years, (1) had to manage on a lower household income, (2) had to draw on savings or get into debt to cover ordinary living expenses, (3) had to cut back on holidays or new household equipment. These three measures have been offered with a seven-point response scale ranging from 0 ('not at all') to 6 ('a great deal'). According to conventional scaling techniques (see Appendix Table 4), these three items form a unidimensional scale that meets statistical tests (Visser et al. 2014; Reeskens and van Oorschot 2014). Moreover, Visser et al. (2014) have demonstrated the cross-national measurement equivalence of this scale, which makes it suitable for comparative research.

\subsection{Moderator Variables}

To untangle whether immaterial buffers from civil society cushion the expected negative impact of experienced hardship on well-being, we first look at informal social ties, which in the present ESS wave is surveyed using the item "How often do you meet socially with friends, relatives or work colleagues?" offered with a seven category response scale ranging from 'never' (0) to 'every day' (6). This survey question has been used in several studies on social networks (Pichler and Wallace 2007; Reeskens and van Oorschot 2014). ${ }^{6}$ The second moderator variable is religious practice, which was surveyed by the question "Apart from special occasions such as weddings and funerals, how often do you attend religious services nowadays?" ranging from 'never' (0) to 'every day' (6). The last variable of interest is confidence in politics, which is measured by a latent scale comprised of how much personal trust one has in the country's parliament, politicians, and political parties. Scaling techniques uncovered that these three trust objects are distinctly different from other institutions of for instance the legal system and the police. The 'confidence in politics'-scale ranges from 'no trust at all' (0) to 'complete trust' (10).

Descriptives of the variables of interest can be found in Appendix Tables 5 and 6. In Table 1 we review the bivariate correlations. Whereas social ties and confidence in politics are positively related to well-being, at the bivariate level there is a weak negative relationship between religious practice and well-being. The latter might be confounded by socioeconomic status (as the lower income groups are on average less happy and at the same time also more religious), which highlights the need for multivariate models. Furthermore, it is noteworthy that economic hardship is reported more among those with fewer social contacts, more religiosity, and those with low confidence in government. Although a more refined analysis would be needed to untangle the detailed causal mechanisms, previous research suggests that poverty leads to social isolation (Gallie et al. 2003; Boehnke 2008). At the same time, social connections, such as a resourceful partner, help unemployed people get a job (Barbieri et al. 2000), and social ties may prevent deprivation

\footnotetext{
${ }^{6}$ On the one hand, we need to be aware that this single ESS-item for informal social bonds is rather crude and does not distinguish between different types of network agents such as friends, relatives and colleagues separately. On the other hand, this measurement serves as a relevant indicator for network access by encompassing various network agents.
} 
Table 1 Correlations between the variables of interest

\begin{tabular}{|c|c|c|c|c|c|}
\hline & $\begin{array}{l}\text { Subjective well- } \\
\text { being }\end{array}$ & $\begin{array}{l}\text { Economic } \\
\text { hardship }\end{array}$ & $\begin{array}{l}\text { Social } \\
\text { contacts }\end{array}$ & $\begin{array}{l}\text { Religious } \\
\text { practice }\end{array}$ & $\begin{array}{l}\text { Confidence in } \\
\text { politics }\end{array}$ \\
\hline $\begin{array}{l}\text { Subjective well- } \\
\text { being }\end{array}$ & 1.000 & $-0.288 * * *$ & $0.242 * * *$ & $-0.024 * * *$ & $0.292 * * *$ \\
\hline $\begin{array}{l}\text { Economic } \\
\text { hardship }\end{array}$ & & 1.000 & $-0.133 * * *$ & $0.049 * * *$ & $-0.232 * * *$ \\
\hline Social contacts & & & 1.000 & $-0.056^{* * *}$ & $0.119 * * *$ \\
\hline $\begin{array}{r}\text { Religious } \\
\text { practice }\end{array}$ & & & & 1.000 & $-0.035^{* * *}$ \\
\hline $\begin{array}{l}\text { Confidence in } \\
\text { politics }\end{array}$ & & & & & 1.000 \\
\hline
\end{tabular}

$* p<0.05 ; * * p<0.01 ; * * * p<0.001$

(Reeskens and van Oorschot 2014). Furthermore, deprived people on average have lower confidence in politics, and recent evidence suggests that they are more likely to turn to religion (Immerzeel and van Tubergen 2013).

In this analysis, we are not examining the extent to which economic hardship affects people's social ties, religious participation or political trust. The focus is instead on the moderating effect of these buffers, to examine the extent to which they might be helpful in maintaining well-being for people who maintain their social ties, religious participation and political trust despite experiencing economic deprivation. However, we need to be aware of potential selection effects affecting our results. If the economically deprived are less likely to maintain social contacts and their confidence in government, then people maintaining social ties and political trust might be a select group who are particularly resilient and who might also be less affected by negative well-being effects. Therefore, the buffers might not be as effective on 'less resilient' people. Unfortunately, our study does not allow for a comprehensive assessment of unobserved characteristics that might be related to both the buffers and the outcome variable, which is a problem shared by all observational studies.

At the country level, we evaluate if the cushioning effect of these protective buffers is weaker in more generous welfare states. Therefore, we consider social expenditure per head of the population (in 1000s euro) for 2010, as obtained from Eurostat. ${ }^{7}$

\subsection{Control Variables}

The correlations indicate that controlling the analyses for relevant variables is required. We control for a U-shaped curvilinear age effect, as previous research shows that middle-aged people are the least happy (Diener and Suh 1998). Although we do not expect strong gender differences in happiness (Myers and Diener 1995), we nonetheless distinguish men (reference) from women. As studies confirm a robust relationship between socioeconomic status and well-being (Myers and Diener 1995), we include level of education (ISCED-

\footnotetext{
7 Other more detailed measures for welfare state generosity have been considered, like the Scruggs et al. (2014) Comparative Welfare Entitlements Dataset. However, the Scruggs dataset lacks information for 2010 - the year the ESS has been fielded - for many Eastern European countries, preventing us from conducting adequate cross-national analysis.
} 
coded), work status and income. Work status is categorized into having paid work (reference category), being unemployed, being a student, being retired, or another status. Selfreported income is also included, which in the ESS is measured using a harmonized 10 -point scale measuring national income deciles. However, because this variable is hampered by a high level of non-response (i.e. $21.3 \%$ ), we imputed the income decile applying regression-based imputation. ${ }^{8}$

To examine the effect of individual economic hardship net of any context effects, we control for the unemployment rate of 2010 (as obtained from Eurostat and from OECD for Switzerland). We expect that well-being is generally lower in countries with high unemployment.

\subsection{Analytical Strategy}

We applied multilevel analysis (Hox 2010), using the maximum likelihood estimator in Stata's xtmixed-procedure. This technique allows us to take into account the nested data structure of the ESS, i.e. residents sampled within countries. Our analytical strategy is as follows: first of all, we assess the bivariate relationship between experienced economic hardship and subjective well-being and in addition, relevant control variables are added in a multivariate design. Secondly, the cushioning role of immaterial protective buffers on the relationship between experienced hardship and subjective well-being is tested to examine whether people who experience hardship report higher levels of subjective well-being if they have access to resources accrued from civil society. Finally, we test for the competing role of welfare state effort; after evaluating if well-being is higher in more generous welfare states, we test if the hypothesized cushioning role of immaterial buffers is lower in welfare states that are more generous by estimating cross-level interactions. ${ }^{9}$

\section{Results}

\subsection{The Relationship between Economic Hardship and Subjective Well-Being}

Table 2 displays the result of four regression models explaining happiness. ${ }^{10}$ At the bivariate level (Model 1), there is a strong bivariate effect of economic hardship on happiness. There is more than one scale point ${ }^{11}(1.332)$ difference between the people who

\footnotetext{
8 The variables used for the imputation are all the individual level variables in our model, supplemented by the following variables which showed the largest correlation with income: personal use of internet; highest level of education; feeling about household income nowadays; did paid work in the last seven days; partner did paid work in the last seven days. The imputation was replicated with multiple imputations, which gave similar results.

9 Due to limited degrees of freedom, we apply random intercepts models. Although random slopes are technically preferred, the power decreases exponentially when more level-1 variables are defined as random. The reason is that every variable that is defined as a random effect requires the estimation of a random slope as well as the covariation between the slope and the intercept. For every additional variable, not only the random slope and the slope-intercept covariation, is estimated, but also the covariation between random slopes of variable A and variable B. To be complete, we have tested the random slopes parameters and cross-level interactions separately (models can be obtained from the authors), and patterns are similar.

10 The control variables largely confirm existing insights as we find a curvilinear age-effect. We further see that women report a higher level of well-being than men. Socioeconomic status (being higher educated, and having a high income) is positively related with happiness.

11 We obtain this parameter by multiplying the scale range (6) by the regression coefficient $(-0.222)$.
} 
Table 2 Economic hardship and its cushioned impact on explaining well-being

\begin{tabular}{|c|c|c|c|c|}
\hline Fixed effects & $\begin{array}{l}\text { Model 1: } \\
\text { hardship }\end{array}$ & $\begin{array}{l}\text { Model 2: } \\
\text { mediators }\end{array}$ & $\begin{array}{l}\text { Model 3: } \\
\text { controls }\end{array}$ & $\begin{array}{l}\text { Model 4: } \\
\text { interactions }\end{array}$ \\
\hline Intercept & $\begin{array}{l}7.597 * * * \\
(0.090)\end{array}$ & $\begin{array}{l}6.139 * * * \\
(0.086)\end{array}$ & $\begin{array}{l}6.069 * * * \\
(0.114)\end{array}$ & $\begin{array}{l}6.429 * * * \\
(0.109)\end{array}$ \\
\hline Economic hardship & $\begin{array}{l}-0.222 * * * \\
(0.005)\end{array}$ & $\begin{array}{l}-0.194 * * * \\
(0.005)\end{array}$ & $\begin{array}{l}-0.135^{* * *} \\
(0.005)\end{array}$ & $\begin{array}{l}-0.271 * * * \\
(0.014)\end{array}$ \\
\hline Social contacts & & $\begin{array}{l}0.230 * * * \\
(0.006)\end{array}$ & $\begin{array}{l}0.200 * * * \\
(0.006)\end{array}$ & $\begin{array}{l}0.146^{* * * *} \\
(0.010)\end{array}$ \\
\hline Religiosity & & $\begin{array}{l}0.047 * * * \\
(0.007)\end{array}$ & $\begin{array}{l}0.072 * * * \\
(0.007)\end{array}$ & $\begin{array}{l}0.051 * * * \\
(0.010)\end{array}$ \\
\hline Confidence in politics & & $\begin{array}{l}0.130 * * * \\
(0.005)\end{array}$ & $\begin{array}{l}0.114 * * * \\
(0.005)\end{array}$ & $\begin{array}{l}0.081 * * * \\
(0.007)\end{array}$ \\
\hline $\begin{array}{l}\text { Economic hardship } \times \text { social } \\
\text { contacts }\end{array}$ & & & & $\begin{array}{l}0.021 * * * \\
(0.003)\end{array}$ \\
\hline Economic hardship $\times$ religiosity & & & & $\begin{array}{l}0.008 * * * \\
(0.003)\end{array}$ \\
\hline $\begin{array}{l}\text { Economic hardship } \times \text { confidence } \\
\text { in politics }\end{array}$ & & & & $\begin{array}{l}0.014 * * * \\
(0.002)\end{array}$ \\
\hline Age & & & $\begin{array}{l}-0.029 * * * \\
(0.003)\end{array}$ & $\begin{array}{l}-0.029 * * * \\
(0.003)\end{array}$ \\
\hline Age squared & & & $\begin{array}{l}0.000 * * * \\
(0.000)\end{array}$ & $\begin{array}{l}0.000^{* * * *} \\
(0.000)\end{array}$ \\
\hline Women & & & $\begin{array}{l}0.120 * * * \\
(0.019)\end{array}$ & $\begin{array}{l}0.121 * * * \\
(0.019)\end{array}$ \\
\hline Levels of education & & & $\begin{array}{l}0.015^{* * *} * \\
(0.006)\end{array}$ & $\begin{array}{l}0.015^{* * * *} \\
(0.006)\end{array}$ \\
\hline \multicolumn{5}{|l|}{ Work status (ref: employed) } \\
\hline Unemployed & & & $\begin{array}{l}-0.298 * * * \\
(0.036)\end{array}$ & $\begin{array}{l}-0.294 * * * \\
(0.036)\end{array}$ \\
\hline Retired & & & $\begin{array}{l}0.044 \\
(0.033)\end{array}$ & $\begin{array}{l}0.037 \\
(0.033)\end{array}$ \\
\hline Other category & & & $\begin{array}{l}0.031 \\
(0.031)\end{array}$ & $\begin{array}{l}0.031 \\
(0.031)\end{array}$ \\
\hline Income & & & $\begin{array}{l}0.150 * * * \\
(0.004)\end{array}$ & $\begin{array}{l}0.150 * * * \\
(0.004)\end{array}$ \\
\hline Imputation dummy & & & $\begin{array}{l}0.021 \\
(0.025)\end{array}$ & $\begin{array}{l}0.015 \\
(0.025)\end{array}$ \\
\hline \multicolumn{5}{|l|}{ Random effects } \\
\hline Individual-level variance & 1.880 & 1.827 & 1.780 & 1.777 \\
\hline Country-level variance & 0.436 & 0.389 & 0.346 & 0.248 \\
\hline
\end{tabular}

Entries represent unstandardized parameter estimates (standard errors between brackets) obtained from four separate regression models

$* p<0.05$; ** $p<001$; *** $p<0.001$

reported highest levels economic hardship and the non-deprived and this is almost twothirds of the standard deviation of reported happiness.

Adding the mediating effect of social contacts, religiosity and confidence in politics (Model 2) slightly reduces the effect of economic hardship, as the effect drops by just over 
$10 \%$, from -0.222 to -0.194 . The fact that people experiencing economic hardship have fewer social contacts and lower political trust explains this reduction, while the frequent church attendance among the economically strained suppresses this effect. Similar to previous studies (Helliwell and Putnam 2004), social networks are positively related to subjective well-being $(b=0.230 ;$ se $=0.006)$. Frequent churchgoers are happier than those who never go to church (Lim and Putnam 2010), though the effect is rather small (0.047; se $=0.007)$. Compared to the reported bivariate relationship in Table 1 , the effect parameter is positive which indicates that the effect of religiosity on well-being is mediated by economic hardship. Furthermore, Europeans with confidence in politics exhibit higher levels of happiness than those who are dissatisfied with politics $(b=0.130$; se $=0.005)$.

The addition of relevant controls (Model 3) further reduces the effect of economic hardship by $31 \%$, showing that $45 \%$ of the standard deviation in happiness can be explained by experiences of economic hardship in the last 3 years. Note that the effect of economic hardship remains highly significant when income and work status are also included, which indicates that the economic hardship variable captures more than income and employment status. Having confidence in politics has the strongest standardized effect $(\beta=0.158)$, followed by the effect of social networks $(\beta=.155)$; the effect of church attendance is comparatively rather small $(\beta=0.053) .{ }^{12}$ In sum, the analysis confirms hypothesis $\mathrm{H} 1$ that economic hardship reduces happiness, and this effect remains substantial after controlling for other material and immaterial resources and the socio-demographic variables.

\subsection{The Buffering Effect of Immaterial Resources}

Model 4 of Table 2 displays interaction tests between the protective buffers and economic hardship on well-being. Firstly, the positive moderating impact of informal social contacts on the relationship between economic hardship and well-being supports hypothesis $\mathrm{H} 2$. Deprived Europeans with frequent social interaction are more likely to be happy, compared to those deprived respondents with weaker social ties. The mechanism is straightforward: people who are deprived might find material and, in particular, immaterial support in their networks that buffers their well-being in the face of economic hardship.

Turning to the moderating effect of religious participation on well-being, the results of Model 4 of Table 2 provide weak support for hypothesis H3. Church practice has only a slight moderating impact on the relationship between economic hardship and happiness. Respondents experiencing economic hardship who frequently attend churches are happier than deprived Europeans who never attend religious services, but the effect is small. In other words, attending religious services buffers economic hardship only slightly. This rather small cushioning effect nuances evidence from American studies (Lim and Putnam 2010).

Lastly, confidence in government confirms proposed hypothesis $\mathrm{H} 4$, as it cushions the negative impact of reported economic hardship on happiness. Deprived respondents who support their national governments are happier than those in economic hardship who think little of politics. Although it is difficult to sustain political trust when undergoing economic

\footnotetext{
12 To calculate the standardized effects, we make use of the formula as provided by Hox (2010, p. 22): standardized coefficient $=[($ unstandardized coefficient $\times$ standard deviation independent variable X)/standard deviation outcome $Y]$.
} 
hardship (see Table 1), people with confidence in government show more resilience against the negative psychological outcomes of economic hardship.

The outcomes of the regression analysis are translated into more comprehensible graphs, based on predicted values of Model 4. All panels of Fig. 1 clearly indicate that the experience of financial shocks in the last 3 years translates into poor well-being.

Observing the moderating effect of the three different immaterial protective measures on the relationship between deprivation and well-being, the graphs show that having

Fig. 1 The moderated effect of informal social contacts, religious participation and political trust on the effect of economic strain (X-axis) on wellbeing (Y-axis)
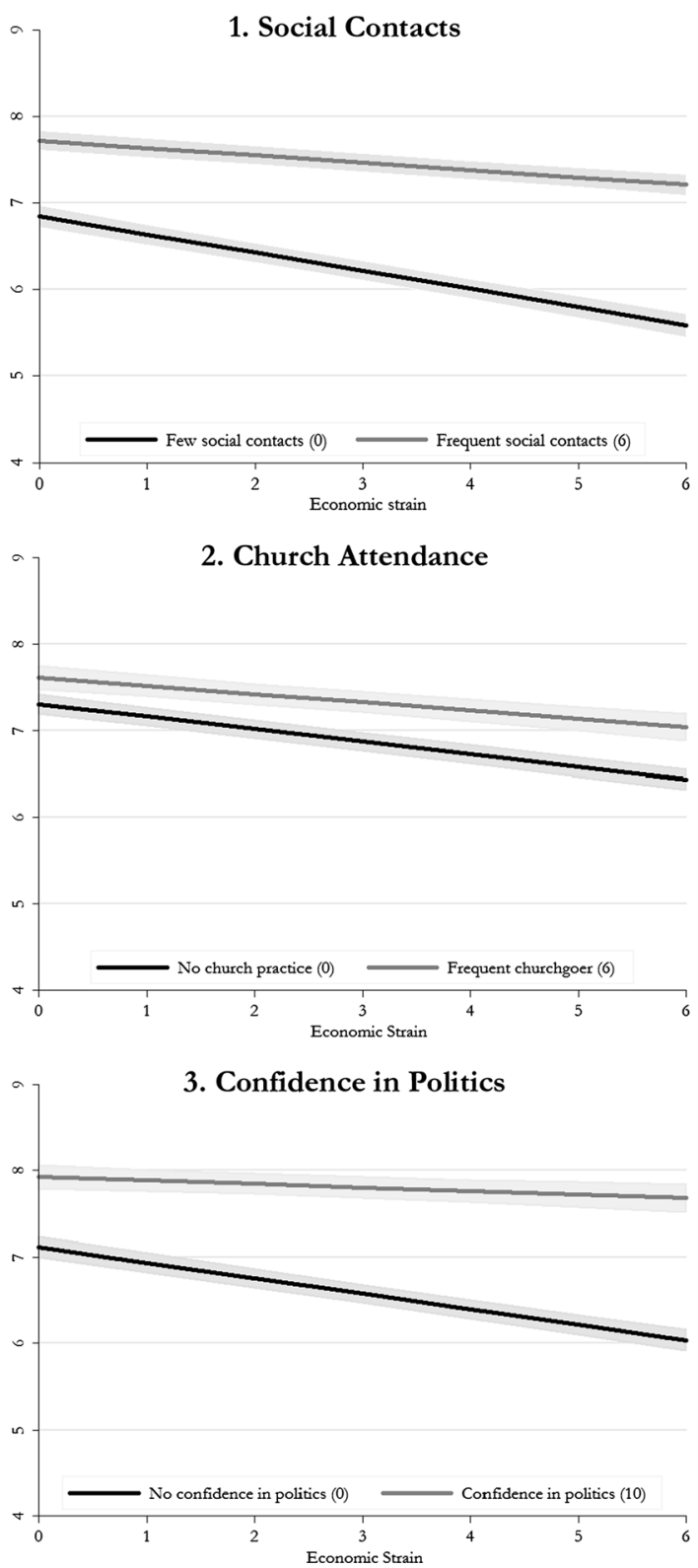
frequent contact with family, friends and colleagues strongly cushions the effect of deprivation on happiness. Whereas the difference in happiness between the highly and nondeprived is about 1.3 among those with very low social contacts, the difference drops to .5 among those with frequent informal contacts. The deprivation effect does not flatten out completely, however. Second, for religious participation, the graph confirms a significant, albeit small, cushioning effect on happiness. The difference in happiness between those who report deprivation is about .9 among the non-frequent churchgoers and about .6 among those who often go to church. Despite significant differences in happiness between frequent churchgoers and those who never go to church, the size of this effect is rather small compared to the effect of informal social contacts and confidence in politics. Lastly, confidence in government strongly cushions the effect of experienced hardship on happiness: whereas among those lacking confidence in government, the difference in happiness between the deprived and non-deprived is about 1.1, this difference is only .25 among those with confidence in government.

\subsection{The Role of Welfare State Effort}

In a final step, we examine whether the effects of the relevant protective buffers are smaller in welfare states that are more generous. We first evaluate the effects of social expenditure on well-being for the full sample, controlled for national unemployment rates. As Table 3 indicates, there is a positive effect of welfare state effort, while there is no independent association between national unemployment level and happiness. ${ }^{13}$ In countries with high per capita spending on social protection, residents report higher levels of well-being than in weaker welfare states.

In a second step, we examine interactions between welfare state effort and the individual immaterial buffers in the whole sample, while we will examine this finding among the most deprived group in step three. ${ }^{14}$ Model 2 of Table 3 shows that across Europe, the positive effect of social contacts on well-being and having confidence in politics is weaker in more generous welfare states. These effects undergird the relevance of the crowding out hypotheses: in larger welfare states, people need to rely less on their immaterial resources for achieving subjective well-being. Interestingly, the effect of religiosity is invariant across welfare states, meaning that in weak and strong welfare states alike, religiosity leads to similar increases in happiness.

Turning our attention to the most deprived group ${ }^{15}$ in a third step, we diagnose effects similar to those of the full sample (Models 3 and 4). Ceteris paribus, we can confirm that the deprived cross-section reports lower levels of happiness, as the intercept is remarkably lower compared with the one of the whole sample. Moreover, there is a slightly larger

\footnotetext{
13 To be complete, at the bivariate level (controlling for individual-level covariates), unemployment rates are affecting well-being negatively, i.e. happiness is lower in countries with high levels of unemployment. However, this effect is mediated by social expenditure.

14 Instead of including three-way interactions between social protection, economic hardship and the three buffers, we have opted to present the analysis in a stratified fashion: first for the whole sample and then for the deprived sub-group. The effects are fairly similar for both groups and also robustness checks with threeway interactions showed no differential effect according to level of economic hardship. In the absence of a significant three-way interactions (see Appendix Table 7), it is confirmed that the moderating effect of the relationship between the immaterial buffers and subjective well-being is the same for the deprived as it is for the non-deprived.

15 This regards the respondents who have given a response of 5 or 6 on the economic hardship scale, which corresponds to about $15 \%$ of the sample.
} 
Table 3 The cushioning impact of welfare state effort on the effect of protective buffers on the well-being of Europeans and deprived Europeans

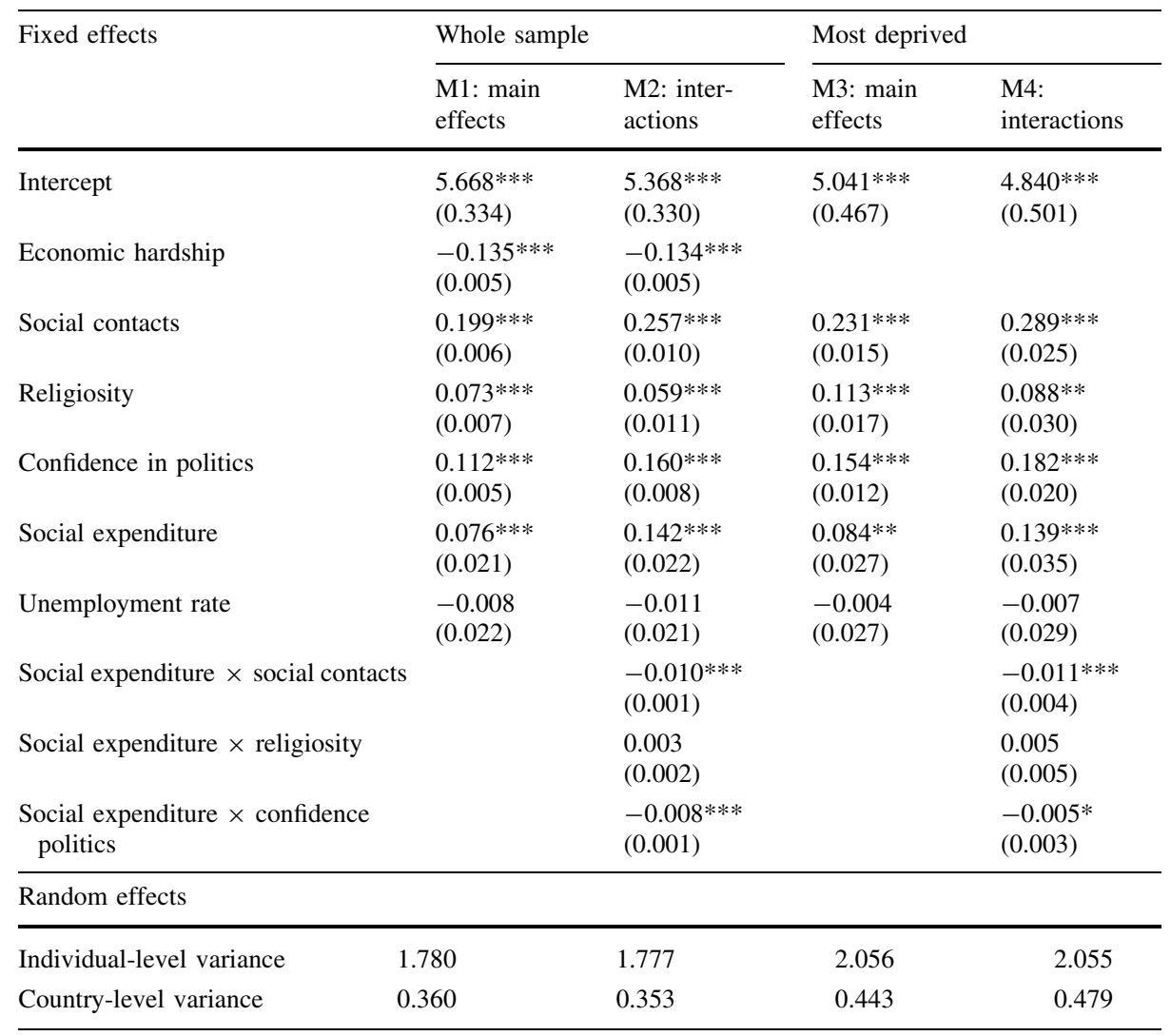

Entries represent unstandardized parameter estimates (standard errors between brackets) obtained from four separate regression models. All models contain the individual level controls as presented in Table 2

$* p<0.05$; ** $p<0.01$; *** $p<0.001$

effect of welfare state effort, while there still is no independent effect of unemployment rates (footnote 13 also holds for the deprived-sample). Importantly, the interaction effects of Model 4 indicate that welfare state effort reduces the positive effect of social networks and confidence in politics among the most deprived to a similar extent as in the whole sample.

The graphs in Fig. 2, based on the results of Model 4 of Table 3, show the extent to which welfare states diminish the effect of the immaterial protective buffers on the wellbeing of the most deprived. The graphs show the effect of the buffers on well-being in Bulgaria and Norway, the countries with respectively the lowest and highest social spending per capita. This graph shows that, controlling for individual covariates and unemployment levels, well-being is higher in countries with higher per capita spending. For social contacts, we see a more positive effect of the frequency of contact on happiness in the weakest welfare state of our study, i.e. Bulgaria, compared with the most generous welfare state, i.e. Norway. However, for deprived people with very frequent social contacts, there is no significant difference in happiness between the least and most generous 
Fig. 2 The moderated effect of welfare state expenditure (per capita) on the effect of protective buffers (X-axis) on well-being (Y-axis) among the deprived

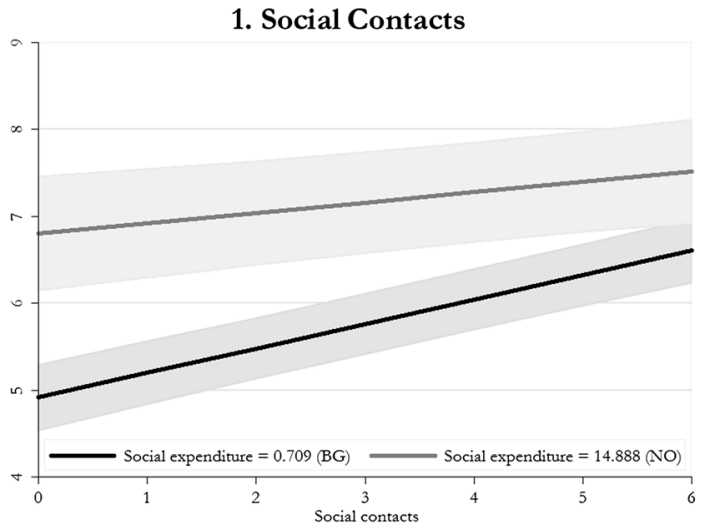

2. Church Attendance

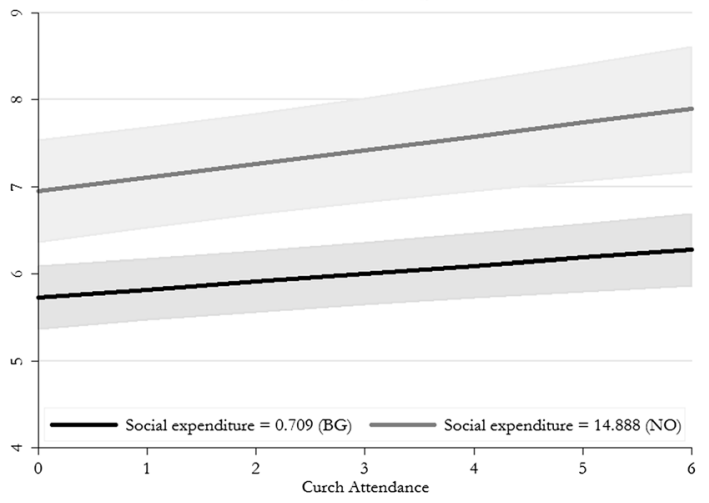

3. Confidence in Government

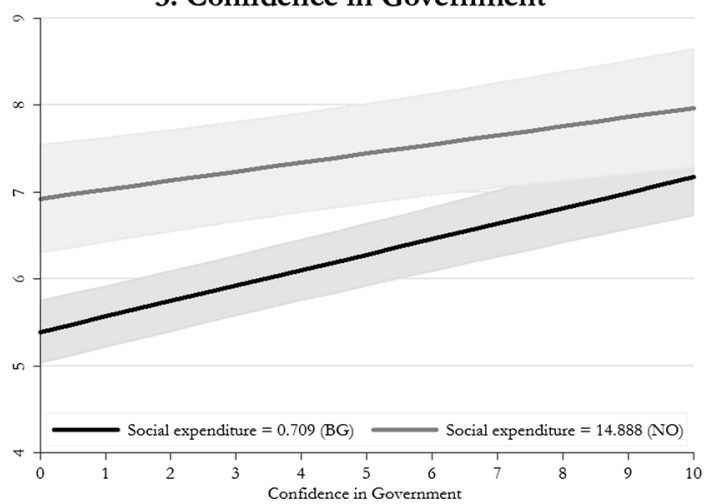

welfare states, showing that in small welfare states, frequent interactions are effective in increasing happiness among the deprived. Church attendance leads to equal increases in happiness in both weak and strong welfare states alike. Lastly, the effect of having confidence in government on well-being is cushioned by welfare expenditure. Interestingly, in weaker welfare states, the impoverished with confidence in government are equally happy as those in generous welfare states who have confidence in government. Put in more 
relative terms, those deprived in weaker welfare states with frequent social contacts or with confidence in government are equally happy as those deprived living in strong welfare states without frequent social contacts and who lack trust in government.

\section{Conclusion}

Social scientists increasingly engage in the study of resilience and try to untangle why some people are better able to overcome economic hardship than others. Whereas studies on resilience in the context of economic hardship have mainly focused on the access of material resources, this study wanted to take a closer look at the access of immaterial resources that accrue from civil society but without losing sight of the fact that such resources may compete with welfare state effort. Due to the cross-sectional design, we were unable to completely tease out the causal mechanisms in great detail. Nevertheless, the discovered patterns largely fit the theoretical assumptions, and give room for additional empirical scrutiny.

Analyzing the 2010 European Social Survey, our study confirmed that immaterial resources accruing from civil society provide resilience in the face of economic hardship. Ties with families, friends and colleagues, reliance on religion, and confidence in politics cushion the negative impact of deprivation on subjective well-being, making the deprived resilient when encountering financial shocks. This should not be surprising, as social networks comprise material as well as immaterial resources, whereas religiosity and confidence in politics provide a sense of control that may alleviate the psychological effects of economic hardship.

While the buffering properties of social ties, religious participation and political trust are all significant, they differ in size and do not completely cancel out the negative relationship between economic hardship and well-being. The cushioning effect of confidence in politics has the largest impact. This is interesting, as it confirms psychological studies (van den Bos et al. 1998) showing that perceptions of fair working institutions are important for positive psychological outcomes. However, while political trust shows the largest buffering potential for the negative effects of deprivation, we need to remember that average levels of confidence in politics are still low among the economically strained. The distribution of social contacts, in comparison, is more even across the scale and among the deprived and non-deprived, which makes informal social networks, from a substantial perspective, the most relevant buffer.

As we demonstrated, immaterial resources matter for dealing with economic hardship; this study aimed at testing whether their cushioning properties are in competition with the material properties of the welfare state. Not unimportantly, our study on European data shows that European welfare states with high per capita spending have happier citizens than weak welfare states, contradicting earlier findings. Of high relevance is the finding that social ties and confidence in politics have a stronger association with happiness in weaker welfare states. Although proponents of the crowding-out thesis (Fukuyama 2001) would find support in this finding for their claim that the welfare state erodes the quality of informal service providers, two important assumptions highlighted by our study cannot be ignored. Firstly, happiness is higher on average in more encompassing welfare states. Secondly, the studied immaterial buffers are generally less present among the most deprived, making welfare state effort an effective resource to enhance the well-being of those encountering hardship. Altogether, the findings shed important nuances to the crowding out thesis. 
Evidently, this study also encounters a number of limitations. First and foremost, it makes use of cross-sectional and observational data and therefore cannot disentangle the more precise causal mechanisms that could be obtained from longitudinal or experimental studies. Economic hardship is asked retrospectively and provides some indication of change over time; when controlled for objective income levels, it captures the effect of economic setbacks well. However, we have no information on changes in other relevant variables, including social contacts, religiosity, confidence in politics and well-being. A reading of the literature nonetheless suggests that the proposed causal mechanisms of this contribution are plausible. Future studies on this topic should focus on panel data across a number of welfare states.

A second limitation is that it is possible that the strong cushioning relationship of confidence in politics on the relationship between economic hardship and happiness discovered is spurious to personality traits or other unobserved characteristics. Indeed, the economically deprived show lower levels of political trust and have less social ties on average. Hence, those who maintain social networks and political trust may be a selected group on unobserved characteristics like emotional stability or other personality traits. The absence of inventories such as the Big Five in the ESS makes refined analyses impossible. Further, some of the included measures lack precision. Whereas our measures for wellbeing and experienced deprivation have passed empirical scrutiny, the indicators for social networks and confidence in politics are rather crude. To give one example, our social contacts indicator does not distinguish between various sources for support, such as family and friends separately.

Thirdly, our study is limited to a few indicators at the country level, whereas other proposed mechanisms may play a role too. A recent study by Delhey and Dragolov (2015) proposed that subjective well-being is nourished in a cohesive context. At the macro level, social cohesion and welfare state expenditure are intertwined yet difficult to causally untoss, as welfare states require social cohesion (cf. Marshall 1950) whereas universal welfare states also breed cohesion (cf. Kumlin and Rothstein 2005; Rothstein and Stolle 2008). The social cohesion index as obtained from the Cohesion Radar project (Bertelsmann-Foundation 2013) and the social expenditure measure in our study correlate .87, making it difficult to distinguish both.

Our study entails a few political implications to help bring resilience in times of hardship. In order to avoid economic deprivation to translate further into poor subjective well-being, governments can play a role by creating conditions in which their citizens can show resilience and best access their resources. Religiosity might be less dependent upon institutional engineering, but social networks and political trust are more tangible. In their continuous effort to combat economic hardship, governments face several challenges such as the extent of budget discipline. Cutting the welfare state might erode social ties and at the same time prevent economies from growing, limiting the economic performance that is vital for confidence in politics. Whether directly, with redistributive measures and social and health policies, or indirectly, with economic political decisions, governments seem to play an important role in the well-being of their populations.

Open Access This article is distributed under the terms of the Creative Commons Attribution 4.0 International License (http://creativecommons.org/licenses/by/4.0/), which permits unrestricted use, distribution, and reproduction in any medium, provided you give appropriate credit to the original author(s) and the source, provide a link to the Creative Commons license, and indicate if changes were made. 


\section{Appendix}

See Tables 4, 5, 6 and 7.

Table 4 Exploratory factor analysis on the socioeconomic deprivation variables

\begin{tabular}{|c|c|c|}
\hline ESS item & Question & $\begin{array}{l}\text { Factor } \\
\text { Loading }\end{array}$ \\
\hline MLOHINC & I have had to manage on a lower household income & 0.805 \\
\hline DSDCLVE & $\begin{array}{l}\text { I have had to draw on my savings or get into debt to cover ordinary living } \\
\text { expenses }\end{array}$ & 0.812 \\
\hline CUTHHEQ & I have had to cut back on holidays or new household equipment & 0.740 \\
\hline
\end{tabular}

Cronbach's alpha: 0.828

Table 5 Descriptive statistics of the continuous variables

Table 6 Descriptive statistics of the categorical variables

\begin{tabular}{lccr}
\hline Variable & Scale & Mean & \multicolumn{1}{l}{ SD } \\
\hline Happiness & $0-10$ & 7.004 & 2.072 \\
Economic hardship & $0-6$ & 2.386 & 1.916 \\
Informal social contacts & $0-6$ & 3.718 & 1.609 \\
Religiosity & $0-6$ & 1.651 & 1.529 \\
Political trust & $0-10$ & 3.411 & 2.276 \\
Age & $14-101$ & 51.314 & 17.150 \\
Level of education & $1-7$ & 3.703 & 1.865 \\
Income & $1-10$ & 5.103 & 2.633 \\
\hline
\end{tabular}

\begin{tabular}{llc}
\hline Variable & Category & Percentage \\
\hline \multirow{2}{*}{ Gender } & Man & 45.9 \\
& Woman & 54.1 \\
Work status & Employed & 50.9 \\
& Unemployed & 8.0 \\
& Retired & 29.0 \\
\multirow{2}{*}{ Missing on income } & Other status & 12.1 \\
& No & 78.7 \\
& Yes & 21.3 \\
\hline
\end{tabular}


Table 7 The cushioning impact of welfare state effort on the effect of protective buffers on the well-being along experiences of deprivation (three-way interaction)

\begin{tabular}{|c|c|c|c|}
\hline \multirow{2}{*}{\multicolumn{2}{|c|}{ Fixed effects }} & \multicolumn{2}{|l|}{ Whole sample } \\
\hline & & M1: main effects & M2: interactions \\
\hline \multicolumn{2}{|l|}{ Intercept } & $\begin{array}{l}5.668 * * * \\
(0.334)\end{array}$ & $\begin{array}{l}5.640 * * * \\
(0.127)\end{array}$ \\
\hline \multicolumn{2}{|l|}{ Economic hardship } & $\begin{array}{l}-0.135 * * * \\
(0.005)\end{array}$ & $\begin{array}{l}-0.266^{* * * *} \\
(0.025)\end{array}$ \\
\hline \multicolumn{2}{|l|}{ Social contacts } & $\begin{array}{l}0.199 * * * \\
(0.006)\end{array}$ & $\begin{array}{l}0.166^{* * * *} \\
(0.018)\end{array}$ \\
\hline \multicolumn{2}{|l|}{ Religiosity } & $\begin{array}{l}0.073 * * * \\
(0.007)\end{array}$ & $\begin{array}{l}0.066^{* * * *} \\
(0.019)\end{array}$ \\
\hline \multicolumn{2}{|l|}{ Confidence in politics } & $\begin{array}{l}0.112 * * * \\
(0.005)\end{array}$ & $\begin{array}{l}0.167 * * * \\
(0.013)\end{array}$ \\
\hline \multicolumn{2}{|l|}{ Social expenditure } & $\begin{array}{l}0.076^{* * * *} \\
(0.021)\end{array}$ & $\begin{array}{l}0.138 * * * \\
(0.012)\end{array}$ \\
\hline \multicolumn{2}{|l|}{ Unemployment rate } & $\begin{array}{l}-0.008 \\
(0.022)\end{array}$ & $\begin{array}{l}-0.002 \\
(0.003)\end{array}$ \\
\hline \multicolumn{3}{|c|}{ Economic hardship $\times$ social contacts } & $\begin{array}{l}0.020^{* * * *} \\
(0.005)\end{array}$ \\
\hline \multicolumn{3}{|c|}{ Economic hardship $\times$ religiosity } & $\begin{array}{l}0.005 \\
(0.006)\end{array}$ \\
\hline \multicolumn{3}{|c|}{ Economic hardship $\times$ confidence in politics } & $\begin{array}{l}0.012 * * * \\
(0.004)\end{array}$ \\
\hline \multicolumn{3}{|c|}{ Social expenditure $\times$ economic hardship } & $\begin{array}{l}0.001 \\
(0.004)\end{array}$ \\
\hline \multicolumn{3}{|c|}{ Social expenditure $\times$ social contacts } & $\begin{array}{l}-0.005 * * \\
(0.002)\end{array}$ \\
\hline \multicolumn{3}{|c|}{ Social expenditure $\times$ religiosity } & $\begin{array}{l}-0.001 \\
(0.002)\end{array}$ \\
\hline \multicolumn{3}{|c|}{ Social expenditure $\times$ confidence in politics } & $\begin{array}{l}-0.009 * * * \\
(0.002)\end{array}$ \\
\hline \multicolumn{2}{|c|}{ Social expenditure $\times$ economic hardship $\times$ social contacts } & & $\begin{array}{l}0.000 \\
(0.001)\end{array}$ \\
\hline \multicolumn{3}{|c|}{ Social expenditure $\times$ economic hardship $\times$ religiosity } & $\begin{array}{l}0.000 \\
(0.001)\end{array}$ \\
\hline \multicolumn{3}{|c|}{ Social expenditure $\times$ economic hardship $\times$ confidence in politics } & $\begin{array}{l}-0.000 \\
(0.001)\end{array}$ \\
\hline \multicolumn{4}{|l|}{ Random effects } \\
\hline Individual-level variance & 1.780 & & 1.775 \\
\hline Country-level variance & 0.360 & & 0.000 \\
\hline
\end{tabular}

Entries represent unstandardized parameter estimates (standard errors between brackets) obtained from four separate regression models. All models contain the individual level controls as presented in Table 2

$* p<0.05$; ** $p<0.01$; *** $p<0.001$ 


\section{References}

Barbieri, P., Paugam, S., \& Russell, H. (2000). Social capital and exits from unemployment. In D. Gallie \& S. Paugam (Eds.), Welfare regimes and the experience of unemployment in Europe (pp. 200-217). New York: Oxford University Press.

Bertelsmann-Foundation. (2013). Social cohesion radar: Measuring common ground. An International Comparison of Social Cohesion. Gütersloh: Bertelsmann Stiftung Publishing.

Boehnke, P. (2008). Are the poor socially integrated? The link between poverty and social support in different welfare regimes. Journal of European Social Policy, 18(2), 133-150.

Bovens, M., \& Wille, A. (2008). Deciphering the Dutch drop: Ten explanations for decreasing political trust in the Netherlands. International Review of Administrative Sciences, 74(2), 283-305.

Brickman, P., \& Campbell, D. (1971). Hedonic relativism and planning the good society. In M. H. Appley (Ed.), Adaptation-level theory: A symposium (pp. 287-302). New York: Academic Press.

Burchardt, T. (2005). Are one man's rags another man's riches? Identifying adaptive expectations using panel data. Social Indicators Research, 74(1), 57-102.

Catterberg, G., \& Moreno, A. (2006). The individual bases of political trust: Trends in new and established democracies. International Journal of Public Opinion Research, 18(1), 31-48.

Clark, A. E., D’Ambrosio, C., \& Ghislandi, S. (2014). Adaptation to poverty in long-run panel data. SOEPpapers on Multidisciplinary Panel Data Research (Vol. 634). Berlin: DIW.

Clark, A. E., Frijters, P., \& Shields, M. A. (2008). Relative income, happiness, and utility. An explanation for the Easterlin paradox and other puzzles. Journal of Economic Literature, 46(1), 95-144.

De Silva, M., McKenzie, K., Harpham, T., \& Huttly, S. (2005). Social capital and mental illness: A systematic review. Journal of Epidemiology and Community Health, 59(8), 619-627.

de Souza Briggs, X. (1998). Brown kids in white suburbs: Housing mobility and the many faces of social capital. Housing Policy Debate, 9(1), 177-221.

Delhey, J., \& Dragolov, G. (2015). Happier together. Social cohesion and subjective well-being in Europe. International Journal of Psychology. doi:10.1002/ijop.12149.

Diener, E., \& Biswas-Diener, R. (2002). Will money increase subjective well-being? A literature review and guide to needed research. Social Indicators Research, 57(2), 119-169.

Diener, E., \& Oishi, S. (2000). Money and happiness: income and subjective well- being across Nations. In E. Diener \& E. Suh (Eds.), Culture and subjective well-being (pp. 185-218). Cambridge: MIT Press.

Diener, E., \& Suh, E. M. (1998). Subjective well-being and age: An international comparison. Annual Review of Gerontology and Geriatry, 17, 304-324.

Diener, E., Suh, E. M., Lucas, R. E., \& Smith, H. L. (1999). Subjective well-being: Three decades of progress. Psychological Bulletin, 125(2), 276-302.

DiTella, R., Haisken-DeNew, J., \& MacCulloch, R. J. (2007). Happiness adaptation to income and to status in an individual panel. Cambridge: National Bureau of Economic Research.

Dolan, P., Peasgood, T., \& White, M. (2008). Do we really know what makes us happy? A review of the economic literature on the factors associated with subjective well-being. Journal of Economic Psychology, 29(1), 94-122.

Durkheim, E. (1951 [1897]). Suicide: A study in sociology. New York: The Free Press.

Easterlin, R. A. (1974). Does economic growth improve the human lot? In P. A. David \& W. B. Melvin (Eds.), Nations and households in economic growth (pp. 89-125). Palo Alto: Stanford University Press.

Easterlin, R. A. (1995). Will raising the incomes of all increase the happiness of all? Journal of Economic Behavior \& Organization, 27(1), 35-48.

Ellison, C. G., \& Levin, J. S. (1998). The religion-health connection. Evidence, theory, and future directions. Health Education and Behavior, 25(6), 700-720.

Emmons, R. A., Cheung, C., \& Tehrani, K. (1998). Assessing spirituality through personal goals. Implications for research on religion and subjective well-being. Social Indicators Research, 45(1-3), $391-422$.

Etzioni, A. (1995). The spirit of community. Hammersmith: Fontana Press.

Ferrer-i-Carbonell, A. (2005). Income and well-being: An empirical analysis of the comparison income effect. Journal of Public Economics, 89(5-6), 997-1019.

Festinger, L. (1954). A theory of social comparison processes. Human Relations, 7, 117-140.

Fukuyama, F. (2001). Social capital, civil society and development. Third World Quarterly, 22(1), 7-20.

Gallie, D., Paugam, S., \& Jacobs, S. (2003). Unemployment, poverty and social isolation. Is there a vicious circle of social exclusion? European Societies, 5(1), 1-32.

George, L. K., Ellison, C. G., \& Larson, D. B. (2002). Explaining the relationship between religious involvement and health. Psychological Inquiry, 13(3), 190-200. 
Gudmundsdottir, D. G. (2013). The impact of economic crisis on happiness. Social Indicators Research, $110(3), 1083-1101$.

Hagerty, M. R. (2000). Social comparisons of income in one's community: Evidence from national surveys of income and happiness. Journal of Personality and Social Psychology, 78(4), 764-771.

Helliwell, J. F. (2003). How's life? Combining individual and national variables to explain subjective wellbeing. Economic Modelling, 20(2), 331-360.

Helliwell, J. F., \& Putnam, R. D. (2004). The social context of well-being. Philosophical Transactions of the Royal Society B: Biological Studies, 359(1449), 1435-1446.

Hox, J. J. (2010). Multilevel analysis. Techniques and applications (2nd ed.). New York: Routledge.

Immerzeel, T., \& van Tubergen, F. (2013). Religion as reassurance? Testing the insecurity theory in 26 European countries. European Sociological Review, 29(2), 359-372.

Kawachi, I., Kennedy, B. P., \& Glass, R. (1999). Social capital and self-rated health: A contextual analysis. American Journal of Public Health, 89(8), 1187-1193.

Kumlin, S., \& Rothstein, B. (2005). Making and breaking social capital: The impact of welfare institutions. Comparative Political Studies, 38(4), 339-365.

Layard, R., Mayraz, G., \& Nickell, S. (2008). The marginal utility of income. Journal of Public Economics, 92(8-9), 1846-1857.

Lim, C., \& Putnam, R. D. (2010). Religion, social networks, and life satisfaction. American Sociological Review, 75(6), 914-933.

Marien, S., \& Hooghe, M. (2011). Does political trust matter? An empirical investigation into the relation between political trust and support for law compliance. European Journal of Political Research, 50(2), 267-291.

Marshall, T. H. (1950). Citizenship and social class and other essays. Cambridge: Cambridge University Press.

Myers, D. G., \& Diener, E. (1995). Who is happy? Psychological Science, 6(1), 10-19.

Narayan, D. (1999). Bonds and bridges. Social capital and poverty. Policy Research Working Paper 2167, Washington D.C.: The World Bank.

Ouweneel, P. (2002). Social security and the well-being of the unemployed in 42 nations. Journal of Happiness Studies, 3(2), 167-192.

Pichler, F., \& Wallace, C. (2007). Patterns of formal and informal social capital in Europe. European Sociological Review, 23(4), 423-435.

Popenoe, D. (1988). Disturbing the nest. Family change and decline in modern society. New York: Aldine de Gruyter.

Putnam, R. D. (2000). Bowling alone. The collapse and revival of American community life. New York: Simon \& Schuster.

Putnam, R. D. (2001). Social capital: Measurement and consequences. Canadian Journal of Policy Research, 2(1), 41-51.

Reeskens, T., \& van Oorschot, W. (2014). European feelings of deprivation amidst the financial crisis. Effects of welfare state effort and informal social relations. Acta Sociologica, 57(3), 191-206.

Rothstein, B., \& Stolle, D. (2008). The state and social capital. An institutional theory of generalized trust. Comparative Politics, 40(4), 441-467.

Scruggs, L., Jahn, D., \& Kuitto, K. (2014). Comparative welfare entitlements data set 2, version $2014-03$. Codebook. Storrs: University of Connecticut.

Stuckler, D., Basu, S., Suhrcke, M., Coutts, A., \& McKee, M. (2011). Effects of the 2008 recession on health: A first look at European data. The Lancet, 378(9786), 124-125.

Stuckler, D., Sanjay, B., Suhrcke, M., Coutts, A., \& McKee, M. (2009). The public health effect of economic crises and alternative policy responses in Europe. The Lancet, 374(9686), 315-323.

Thibaut, J., \& Walker, L. (1975). Procedural justice: A psychological analysis. Hillsdale: Lawrence Erlbaum.

Uphoff, E. P., Pickett, K. E., Cabieses, B., Small, N., \& Wright, J. (2013). A systematic review of the relationships between social capital and socioeconomic inequalities in health. A contribution to understanding the psychosocial pathway of health inequalities. International Journal of Equity in Health, 12(1), 54-66.

van den Bos, K., Lind, E. A., Vermunt, R., \& Wilke, H. A. M. (1997). How do I judge my outcome when I do not know the outcome of others? The psychology of the fair process effect. Journal of Personality and Social Psychology, 72(5), 1034-1046.

van den Bos, K., Wilke, H. A. M., Lind, E. A., \& Vermunt, R. (1998). Evaluating outcomes by means of the fair process effect: Evidence for different processes in fairness and satisfaction judgments. Journal of Personality and Social Psychology, 74(6), 1493-1503. 
van Oorschot, W., \& Arts, W. (2005). The social capital of European welfare states. The crowding out hypotheses revisited. Journal of European Social Policy, 15(1), 5-26.

Veenhoven, R. (2000). Well-being in the welfare state: Level not higher, distribution not more equitable. Journal of Comparative Policy Analysis, 2(1), 91-125.

Veenhoven, R., \& Ehrhardt, J. (1995). The cross-national pattern of happiness: Test of predictions implied in three theories of happiness. Social Indicators Research, 34(1), 33-68.

Visser, M., Gesthuizen, M., \& Scheepers, P. (2014). The impact of macro-economic circumstances and social protection expenditure on economic deprivation in 25 European countries, 2007-2011. Social Indicators Research, 115(3), 1179-1203.

Walzer, M. (1995). The concept of civil society. In M. Walzer (Ed.), Toward a global civil society (pp. 7-27). Providence: Berghahn Books.

Wolbring, T., Keuschnigg, M., \& Negele, E. (2013). Needs, comparisons, and adaptation: The importance of relative income for life satisfaction. European Sociological Review, 29(1), 96-104. 